P-ISSN 2580 - 7781

E-ISSN $2615-3238$

\title{
KLASIFIKASI TWEET INFLUENCER NU DENGAN GNPF-ULAMA MENGGUNAKAN NAIVE BAYES DAN SUPPORT VECTOR MACHINE
}

\section{CLASSIFICATION OF NU INFLUENCER TWEET WITH GNPF-ULAMA USING NAIVE BAYES AND SUPPORT VECTOR MACHINE}

\author{
Andi Taufik ${ }^{1)}$, Robi Sopandi ${ }^{2)}$ \\ ${ }^{1}$ Program Studi Sistem Informasi, Universitas Nusa Mandiri \\ ${ }^{2}$ Program Studi Teknik Informatika, Universitas Nusa Mandiri \\ ${ }^{1}$ Email: robi.rbs@nusamandiri.ac.id
}

\begin{abstract}
ABSTRAK
Legitimasi sebagai kelompok yang paling mewakili umat terus menjadi hal yang diperebutkan oleh kelompok Islam saat ini. Di satu sisi ada Nahdlatul Ulama (NU) dengan wacana Islam dan nasionalisme, di sisi lain ada Gerakan Nasional Pembela Fatwa Ulama (GNPF-Ulama) dengan wacana yang hanya menekankan pada aspek Islam. Pertarungan wacana kedua kelompok besar ini termasuk di media sosial Twitter sontak menimbulkan kebingungan pada umat Islam terutama yang awam, ditambah lagi banyaknya Buzzer dan Influencer yang berafiliasi kepada masing-masing kelompok. Penelitian ini akan melakukan klasifikasi tweet dari Influencer yang berafiliasi dengan NU dan GNPF-Ulama di media sosial Twitter. Algoritma yang digunakan adalah Naive Bayes dan Support Vector Machine. Data Twitter diambil menggunakan library tweepy, proses preprocessing menggunakan Python dengan penggunaan Library Sastrawi untuk melakukan stemming kata bahasa Indonesia. Klasifikasi dengan metode Naive Bayes dan Support Vector Machine dilakukan menggunakan aplikasi RapidMiner. Dari rangkaian proses yang dilakukan, metode Support Vector Machine menghasilkan nilai akurasi dan AUC yang lebih baik dari Naive Bayes yakni sebesar 77.28\% dan AUC sebesar 0.863.

Kata kunci: Klasifikasi, Nahdlatul ulama, GNPF-Ulama, Naive bayes, Support vector machine
\end{abstract}

\begin{abstract}
Legitimacy as the group that best represents the ummah continues to be contested by Islamic groups today. On the one hand there is the Nahdlatul Ulama (NU) with the discourse of Islam and nationalism, on the other hand there is Gerakan Nasional Pembela Fatwa Ulama (GNPF-Ulama) with a discourse that only emphasizes the Islamic aspect. The battle between the two major groups, including on social media, Twitter, suddenly caused confusion among Muslims, especially the layman, plus the large number of Buzzers and Influencers affiliated with each group. This research will classify tweets from influencers affiliated with NU and GNPF-Ulama on twitter. The algorithm used is Naive Bayes and Support Vector Machine. Twitter data is taken using the Tweepy library, the preprocessing process uses python with the use of the Sastrawi library to stem Indonesian words. Classification using the Naive Bayes method and Support Vector Machine is done using the RapidMiner application. From the circuit process carried out, the Support Vector Machine method produced better accuracy and AUC values than Naive Bayes, namely $77.28 \%$ and AUC of 0.863 .
\end{abstract}

Keywords: Classification, Naive bayes, Support vector machine, Nahdlatul ulama, GNPF-Ulama 


\section{PENDAHULUAN}

Populisme Islam belakangan ini merupakan salah satu topik sentral dalam kajian politik di Indonesia. Legitimasi sebagai kelompok yang paling mewakili umat menjadi hal yang diperebutkan oleh kelompok Islam saat ini. Pertarungan wacana khususnya yang terjadi antara kelompok GNPF-Ulama yang dimotori oleh FPI dengan kelompok NU sebagai organisasi Islam terbesar di Indonesia terus terjadi di berbagai tempat dan media termasuk media sosial (Jayanto, 2019).

Nahdlatul Ulama (NU) atau dalam bahasa Indonesia artinya "Kebangkitan Para Ulama" merupakan ormas Islam terbesar di Indonesia saat ini. Sebagai organisasi yang memiliki nasionalisme sebagai salah satu motif berdirinya, militansi dan semangat kelompok NU dalam membela negara sangat tinggi. NU aktif mensosialisasikan NKRI sebagai bentuk final dari sistem kebangsaan di Indonesia. Sehingga dalam pergerakannya saat ini, NU aktif melawan gerakan separatisme, radikalisme, dan konflik antar ras karena dianggap bisa menimbulkan disintegrasi dan memecah belah bangsa (Farih, 2016).

Berbeda dengan NU menggunakan dimensi keagamaan dan nasionalisme dalam wacananya, Gerakan Nasional Pembela Fatwa Ulama (GNPF-Ulama) merupakan gerakan yang menekankan aspek wacana keagamaan sehingga membentuk legitimasi populisme Islam. Gerakan yang dimotori oleh Front Pembela Islam (FPI) dengan Habib Rizieq sebagai tokoh sentralnya ini membingkai aktivitas dan gerakan berbasiskan pada identitas kesamaan agama. Hal ini tidak terlepas dari kegeraman atas janji-janji penguasa yang tidak kunjung terwujud sehingga menjadi alternatif untuk menyelesaikan persoalan dengan merebut sumber daya dan kekuasaan dalam negeri (Jayanto, 2019).

Saat ini, baik NU dan GNPF-Ulama terus melakukan kontestasi dalam memperebutkan wacana sebagai perwakilan Islam di Indonesia dalam bentuk narasi yang berbeda. NU dengan Islam dan nasionalisme sebagai wacana sedangkan GNPF-Ulama hanya menekankan pada aspek Islam (Jayanto, 2019). Salah satu contoh pertarungan wacana antara kedua kelompok ini adalah ketika pada tahun pemilihan Presiden 2019, ketua umum NU yaitu KH. Ma'ruf Amin 
P-ISSN 2580 - 7781

E-ISSN 2615 - 3238

yang mencalonkan diri sebagai wakil presiden berhadapan langsung dengan Prabowo yang didukung langsung oleh GNPF-Ulama melalui Ijtima Ulama mereka. Pertarungan wacana kedua kelompok besar ini termasuk di media sosial sontak menimbulkan kebingungan pada umat Islam terutama yang awam, ditambah lagi banyaknya Buzzer dan Influencer yang berafiliasi kepada masingmasing kelompok meski tidak menampakkan keterkaitannya secara langsung.

Meskipun demikian, kita dapat menggunakan data dari salah satu media sosial yang digunakan yaitu Twitter sebagai bahan untuk mengklasifikasikan tweet mereka menggunakan teknik data mining sehingga bisa terlihat afiliasinya meskipun tidak disebut secara langsung. Metode yang digunakan pada penelitian ini adalah Naive Bayes dan Support Vector Machine. Penelitian ini akan membandingkan akurasi pada penggunaan metode Naive Bayes dan Support Vector Machine setelah sebelumnya data dibersihkan melalui tahap preprocessing terlebih dahulu. Kedua metode ini sudah banyak digunakan oleh para peneliti terutama pada data yang berasal dari Twitter untuk analisa sentimen dengan mengelompokkan teks apakah bermuatan positif atau negatif.

Selain untuk analisa sentimen, penggunaan kedua metode untuk klasifikasi tweet juga pernah dilakukan seperti yang dilakukan oleh Baydhowi, Apriliah, dan Kurniawan yang menggunakan metode Naive Bayes untuk mengklasifikasikan tweet berdasarkan keterkaitan tweet terhadap topik retail, proyek, dan pendidikan. Hasil dari percobaan yang dilakukan memiliki tingkat lebih dari $40 \%$ sehingga akurasi yang didapat termasuk ke dalam kategori kurang baik (Baydhowi et al, 2019).

Metode Support Vector Machine juga banyak digunakan untuk klasifikasi tweet seperti yang dilakukan oleh Purnamasari dkk pada penelitian yang menggunakan metode Support Vector Machine untuk mengklasifikasikan tweet yang mengandung konten bullying. Hasil akurasi yang didapatkan dengan metode Support Vector Machine adalah 75\% (Purnamasari et al, 2018).

Dengan adanya variasi akurasi yang didapat dari kedua metode ini, mendorong penulis untuk melakukan penelitian dengan membandingkan metode Naive Bayes dan Support Vector Machine. Penelitian ini akan membahas tahapan 
yang dilalui untuk melakukan klasifikasi tweet dari Influencer NU dan GNPFUlama melalui media sosial Twitter. Proses dimulai dari tahap preprocessing menggunakan Python sampai tahap klasifikasi dengan Naive Bayes dan Support Vector Machine menggunakan aplikasi RapidMiner.

\section{METODE PENELITIAN}

\section{Klasifikasi Bayes}

Klasifikasi Bayes merupakan metode yang dikembangkan dari teorema Bayes. Pada penerapan suatu model, kadangkala kita sudah memiliki prior belief (keyakinan awal) pada suatu parameter tentang kemungkinan nilainya. Dalam metode Bayes, untuk mengestimasi parameter keyakinan awal dimasukkan ke dalam perhitungan. Peluang pada teorema Bayes dinyatakan sebagai berikut:

$$
P(H \mid X)=\frac{P(X \mid H) P(H)}{P(X)}
$$

Di mana $\mathbf{H}$ adalah hipotesis, $\mathbf{X}$ adalah bukti, $\mathbf{P}(\mathbf{H} \mid \mathbf{X})$ adalah probabilitas posterior $\mathrm{H}$ dengan syarat $\mathbf{X}$ atau dengan kata lain peluang hipotesis $\mathbf{H}$ benar untuk bukti $\mathbf{X}$. $\mathbf{P}(\mathbf{X} \mid \mathbf{H})$ adalah probabilitas posterior $\mathbf{X}$ dengan syarat $\mathbf{H}$ atau peluang bukti $\mathbf{X}$ benar untuk hipotesis $\mathbf{H}, \mathbf{P}(\mathbf{X})$ adalah probabilitas prior bukti $\mathbf{X}$ dan $\mathbf{P}(\mathbf{H})$ adalah probabilitas prior hipotesis H (Suyanto, 2019). Di antara kelebihan pada klasifikasi Naive Bayes antara lain:

1. Mudah dipahami

2. Mampu menangani data diskrit dan kuantitatif

3. Hanya memerlukan sedikit data latih untuk estimasi parameter yang dibutuhkan dalam klasifikasi

4. Kokoh untuk titik noise yang diisolasi dan atribut yang tidak relevan (Jollyta et al, 2020).

\section{Support Vector Machine}

SVM berkaitan dengan memaksimalkan jarak pemisah antar kelas data (margin). Mencari hyperplane terbaik dengan cara memisahkan dua kelas data merupakan konsep dasar dari SVM. 


\section{P-ISSN 2580 - 7781}

E-ISSN 2615 - 3238

Sebuah hyperplane yang paling baik adalah yang mampu mengklasifikasikan kedua kelas dengan jarak yang paling lebar. Sehingga pada kedua gambar di atas, Hyperplane 1 lebih baik karena memiliki margin yang lebih besar. Adapun yang disebut Support Vector adalah objek-objek data terluar yang paling dekat dengan hyperplane. Karena posisinya yang hampir tumpang tindih, support vector inilah yang diperhitungkan untuk menemukan hyperplane yang paling optimal. Kelebihan dari metode SVM antara lain:

1. Relatif mudah diimplementasikan.

2. Kemampuan generalisasi yang tinggi terhadap data.

3. Meskipun dilatih dengan himpunan data yang relatif sedikit, SVM dapat menghasilkan model klasifikasi yang baik (Suyanto, 2019).

\section{Tahapan Penelitian}

Penelitian ini terdiri dari 5 tahapan yang mengacu pada metodologi CRISPDM (Cross Industry Standard Process for Data Mining). Pada ada metodologi CRISP-DM terdapat 6 tahapan yaitu, Business Understanding, Data Understanding, Data Preparation, Modelling, Evaluation, dan Deployment. Namun pada penelitian ini, penulis tidak melakukan proses Deployment. 
Berikut ini adalah kerangka alur pada penelitian ini:

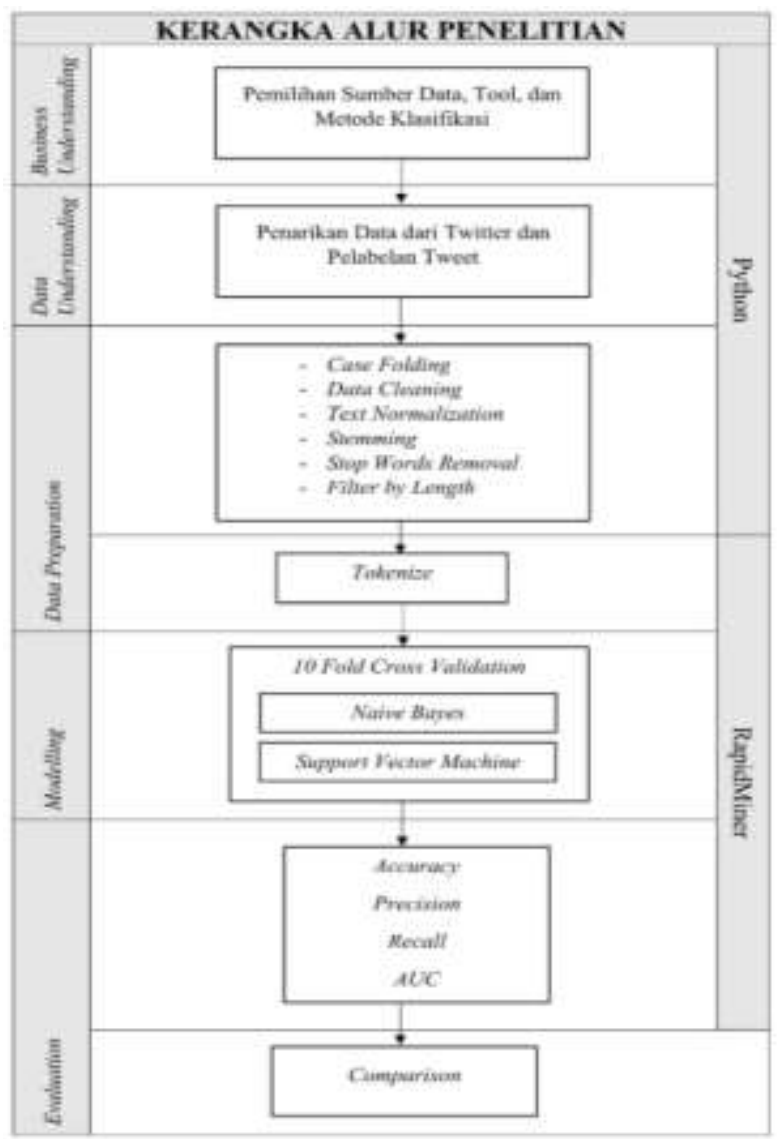

Gambar 1. Kerangka Alur Penelitian

\section{HASIL DAN PEMBAHASAN}

\section{Business Understanding}

Tahapan pada penelitian ini dimulai dengan business understanding. Pada tahap ini, dilakukan pemahaman terhadap objek yang diteliti. Dimulai dari mengenali akun yang cocok dijadikan sampel untuk diambil tweetnya, yakni akun yang memiliki basis pengikut tinggi, status pemiliknya yang merupakan tokoh maupun pengurus dari kelompok NU ataupun GNPF-Ulama.

Pada tahap ini juga dilakukan penentuan algoritma yang digunakan untuk melakukan klasifikasi. Karena proses pada penelitian ini adalah mengklasifikasikan tweet dari dua kelompok yang berbeda. Maka dipilih algoritma yang masuk ke dalam kategori algoritma untuk melakukan klasifikasi yaitu Naive Bayes dan Support Vector Machine. Termasuk juga pada fase ini menentukan tool yang akan digunakan untuk mempersiapkan data dan pemodelan. 


\section{Data Understanding}

Pada tahap ini, dilakukan pengambilan yang dibutuhkan untuk penelitian.

Data diambil menggunakan library tweepy dengan bahasa pemrograman Python.

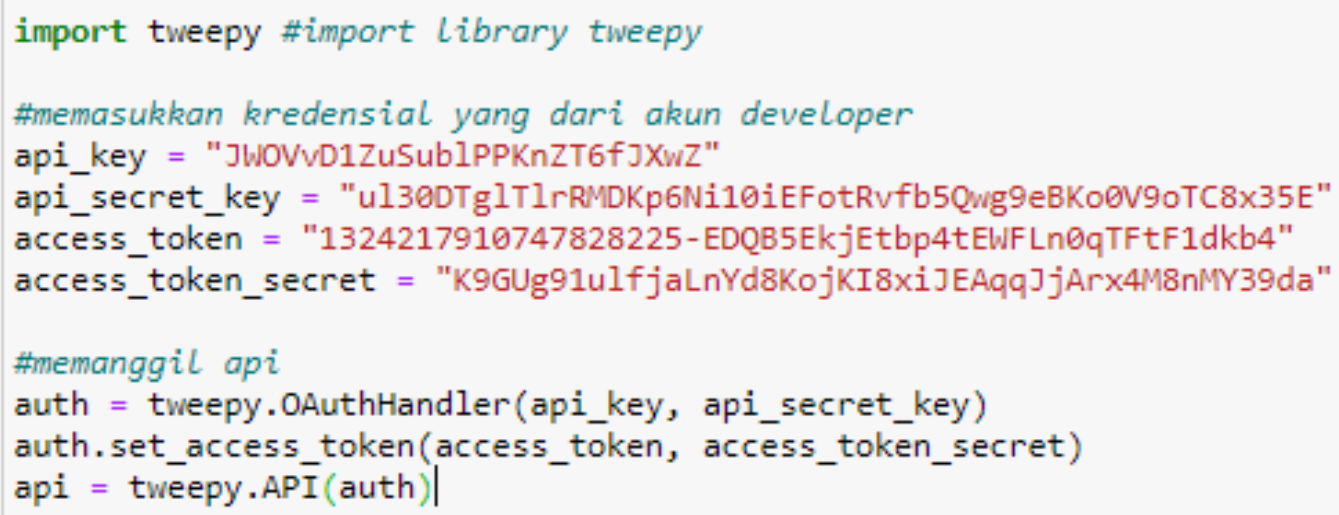

Gambar 2. Mengimpor Library Tweepy

Sebelum bisa digunakan, sebuah library harus diimpor terlebih dahulu. Selanjutnya kode kredensial yang sudah didapatkan melalui developer.twitter.com dimasukkan agar kemudian bisa menggunakan twitter api untuk mendapatkan data tweet.

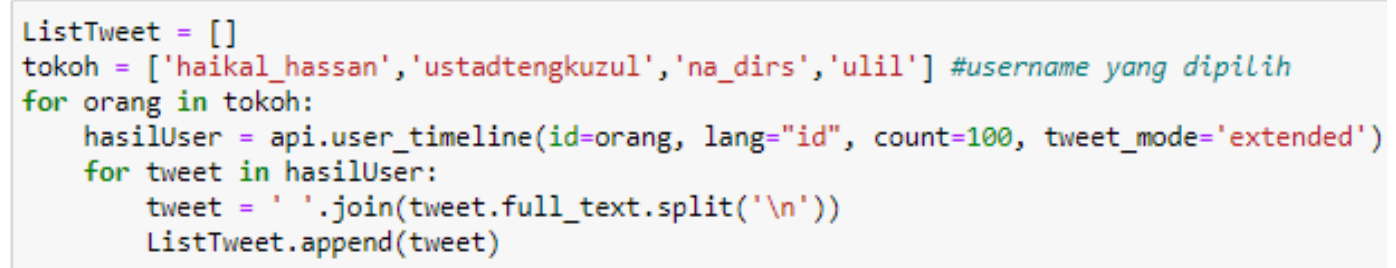

Gambar 3. Mengambil Data Tweet

Untuk mengambil pertama ditentukan username yang ingin diambil data tweetnya. Selanjutnya dilakukan looping untuk pengambilan data pada masingmasing username. Data yang didapat bervariasi mulai dari id, created_at, url, location, user_mentions, tweet, dan lain sebagainya. Karena pada penelitian ini hanya menggunakan tweet maka data yang diambil hanya data full_text untuk menampilkan teks penuh dari tweet yang diambil. Setiap tweet yang didapat lalu dimasukkan ke dalam variabel ListTweet untuk kemudian diekspor ke dalam format excel. 


\section{import pandas as pd \\ pd.DataFrame(ListTweet).to_excel('nu_gnpf.xlsx', index=False)}

Gambar 4. Ekspor Tweet ke dalam Bentuk Excel.

Untuk mengekspor kumpulan tweet pada variabel ListTweet ke dalam bentuk excel, penulis menggunakan library bernama pandas. Variabel ListTweet dikonversi terlebih dahulu ke dalam bentuk DataFrame untuk kemudian diekspor ke dalam bentuk excel. Total data yang diambil sejumlah 400 tweet dalam rentang tanggal 23 hingga 30 November 2020, masing-masing 200 tweet dari kelompok NU dan 200 tweet dari kelompok GNPF-Ulama dengan rincian 100 tweet untuk tiap username. Setelah diekspor ke dalam bentuk excel, setiap tweet lalu dilabeli secara manual untuk kemudian dilakukan preprocessing pada tahap selanjutnya.

Tabel 1. Contoh Data Tweet yang diambil

\begin{tabular}{|l|l|}
\hline \multicolumn{1}{|c|}{ Label } & \multicolumn{1}{|c|}{ Tweet } \\
\hline GNPF-U & $\begin{array}{l}\text { Heran!!! Sekedar general check-up diframming sedemikian rupa } \\
\text { terpapar Covid19. Lalu harus laporkan hasil lah Lalu gak ikut } \\
\text { prosedur lah Lalu dituduh kabur lah Bangsa ini terlalu berani } \\
\text { menyudutkan, memojokkan, mencari2 kesalahan, menyusahkan } \\
\text { ulama habaib. Tunggu! }\end{array}$ \\
\hline GNPF-U & $\begin{array}{l}\text { Semua masalah negara, korupsi, omnibus law, ciptakerja, partai, } \\
\text { pertumbuhan ekonomi minus, hutang ugal2an, reklamasi, dll } \\
\text { semua lenyap, tenggelam berganti dengan RS.UMMI Bogor. } \\
\text { Sampai kapan begini? }\end{array}$ \\
\hline NU & $\begin{array}{l}\text { Sedikit tentang Kiai Miftachul Akhyar yg didaulat sebagai Ketum } \\
\text { pundangan keagamaan, beliau adalah sosok konservatif yg } \\
\text { moderat, khas para kiai pada umumnya. }\end{array}$ \\
\hline NU & $\begin{array}{l}\text { Gus Dur itu melampaui standar pemahaman kita ttg sosok Kiai. } \\
\text { Sampai sekarang saja masih banyak yang kaget kalau Kiai bicara } \\
\text { soal bola, musik, politik, puisi, atau bahkan tik-tok Mereka } \\
\text { sangka urusannya Kiai itu cuma soal khutbah dan khitbah } \\
\text { hehehhe https://t.co/bOZQsTpkly }\end{array}$ \\
\hline
\end{tabular}




\section{P-ISSN $2580-7781$}

E-ISSN $2615-3238$

\section{Data Preparation}

Setelah data diambil, tahap selanjutnya dalah melakukan persiapan data. Pada tahap ini dilakukan beberapa langkah yang disebut dengan text preprocessing. Tahap ini terdiri dari 7 langkah, 6 tahap dilakukan menggunakan Python dan 1 tahap dilakukan dengan menggunakan RapidMiner.

\section{a. Case Folding}

Dalam suatu teks, tidak semua kata konsisten dituliskan dalam bentuk yang sama. Pada tahap ini, teks dikonversi menjadi bentuk standar antara huruf kecil atau huruf besar secara keseluruhan. Proses ini dilakukan menggunakan fungsi bawaan dari Python.

\section{def lowercase(text): return text.lower()}

Gambar 5. Merubah Teks menjadi Huruf Kecil

Tabel 2. Sebelum dan Sesudah Proses Case Folding

\begin{tabular}{|l|l|}
\hline \multicolumn{1}{|c|}{ Sebelum } & \multicolumn{2}{|c|}{ Sesudah } \\
\hline JANGAN POLITIK TERUS.... SEKARANG & jangan politik terus.... sekarang kita \\
KITA SEMINAR KHUSUS UTK WANITA & seminar khusus utk wanita agar segera \\
AGAR SEGERA DPT PASANGAN YANG & dpt pasangan yang jujur dan tg.jawab... \\
JUJUR DAN TG.JAWAB... & \\
\hline
\end{tabular}

\section{b. Data Cleaning}

Setelah semua kata sama rata dari sisi penggunaan huruf besar dan kecil. Tahap selanjutnya adalah membersihkan data dari karakter-karakter yang tidak penting antara lain simbol retweet (RT), tanda mention kepada pengguna lain (@username), URL, spasi berlebih, dan alfanumerik. 


\section{P-ISSN 2580 - 7781}

E-ISSN $2615-3238$

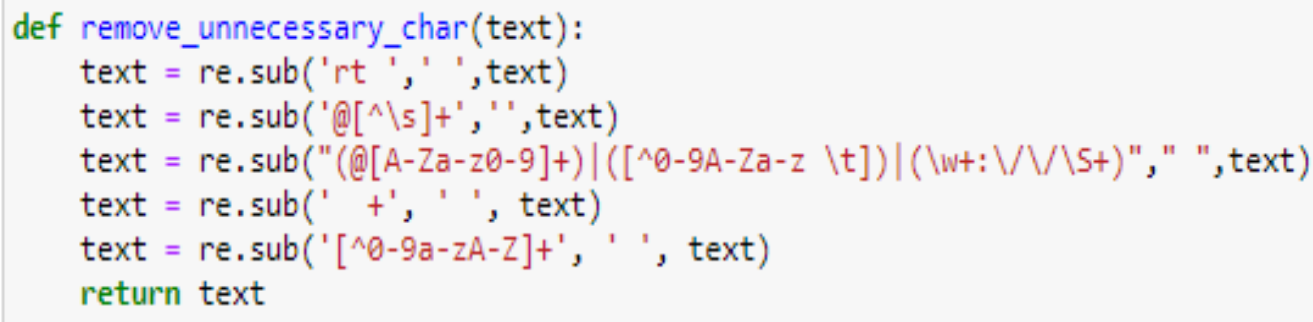

Gambar 6. Membersihkan Data dari Karakter yang Tidak Penting

Tabel 3. Sebelum dan Sesudah Proses Data Cleaning

\begin{tabular}{|c|c|}
\hline Sebelum & Sesudah \\
\hline $\begin{array}{l}\text { Kenapa babe Haikal minta maaf? Ada di } \\
\text { Podcast Deddy Corbuzier } \\
\text { https://t.co/J4248gfch4 } \\
\text { https://t.co/a2TS3USCR4 }\end{array}$ & $\begin{array}{l}\text { Kenapa babe Haikal minta maaf Ada di } \\
\text { Podcast Deddy Corbuzier }\end{array}$ \\
\hline
\end{tabular}

\section{c. Text Normalization}

Dalam menulis sesuatu, terkadang seseorang menggunakan cara penulisan yang bermacam-macam baik menggunakan kata tidak baku ataupun singkatan. Pada tahap ini kata dirubah dari bentuk tidak formal menjadi formal. Penelitian ini menggunakan dataset yang dibuat oleh Muhammad Okky Ibrohim dan Indra Budi untuk melakukan normalisasi teks (Ibrohim and Budi, 2019).

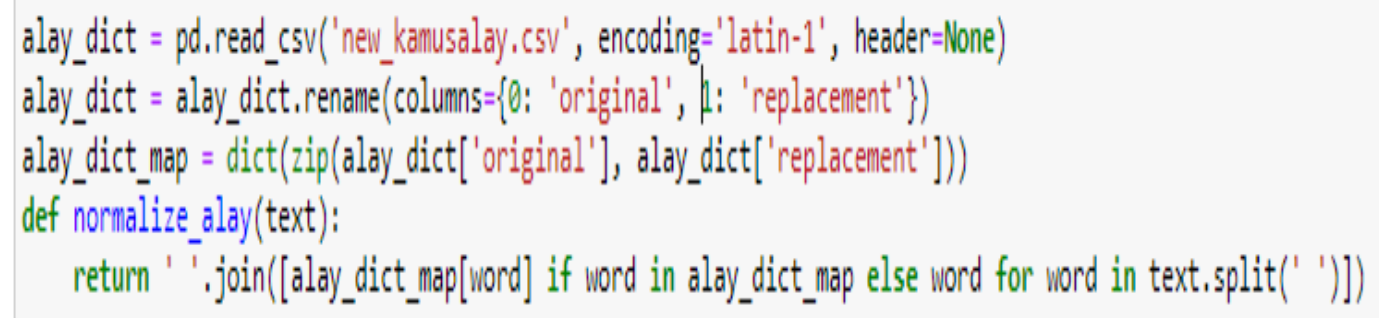

Gambar 7. Normalisasi Teks

Tabel 4. Sebelum dan Sesudah Text Normalization

\begin{tabular}{|l|l|}
\hline \multicolumn{1}{|c|}{ Sebelum } & \multicolumn{1}{c|}{ Sesudah } \\
\hline $\begin{array}{l}\text { Semua survey tiba2 rontok dengan berita } \\
\text { menggelegar ini }\end{array}$ & $\begin{array}{l}\text { Semua survei tiba tiba rontok dengan berita } \\
\text { menggelegar ini }\end{array}$ \\
\hline
\end{tabular}


P-ISSN 2580 - 7781

E-ISSN $2615-3238$

\section{d. Stemming}

Pada proses Stemming, data ditransformasikan menjadi kata dasarnya. Hal ini dilakukan dengan menghilangkan awalan dan akhiran pada turunan kata. Untuk melakukan proses stemming, penelitian ini menggunakan library Python Sastrawi yang merupakan pengembangan dari library Sastrawi pada bahasa pemrograman PHP.

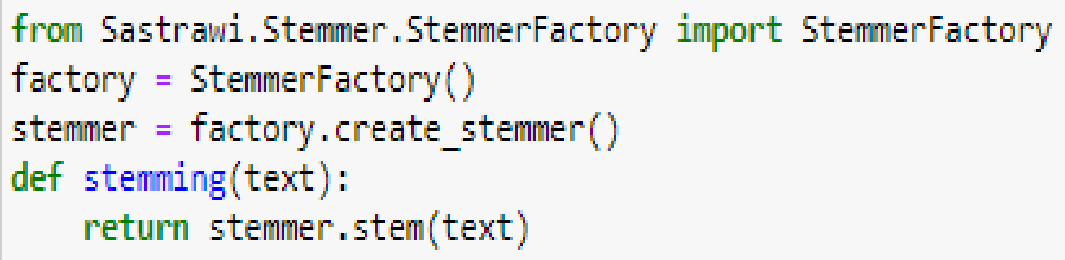

Gambar 8. Stemming menggunakan Library Sastrawi

Tabel 5. Sebelum dan Sesudah Proses Stemming

\begin{tabular}{|l|l|}
\hline \multicolumn{1}{|c|}{ Sebelum } & \multicolumn{1}{|c|}{ Sesudah } \\
\hline $\begin{array}{l}\text { Jangan bercerai berai... Berbeda itu nggak } \\
\text { apa apa }\end{array}$ & jangan cerai berai beda itu nggak apa apa \\
\hline
\end{tabular}

\section{e. Stop Words Removal}

Pada tahap ini kata umum yang seringkali muncul dalam jumlah besar dan tidak memiliki pengaruh besar terhadap makna dihapus. Penelitian ini menggunakan dataset dari kaggle bernama Indonesian Stoplist (Oswin Rahadiyan Hartono 2016) yang dibuat berdasarkan penelitian oleh Fadillah Tala (Tala, 2003).

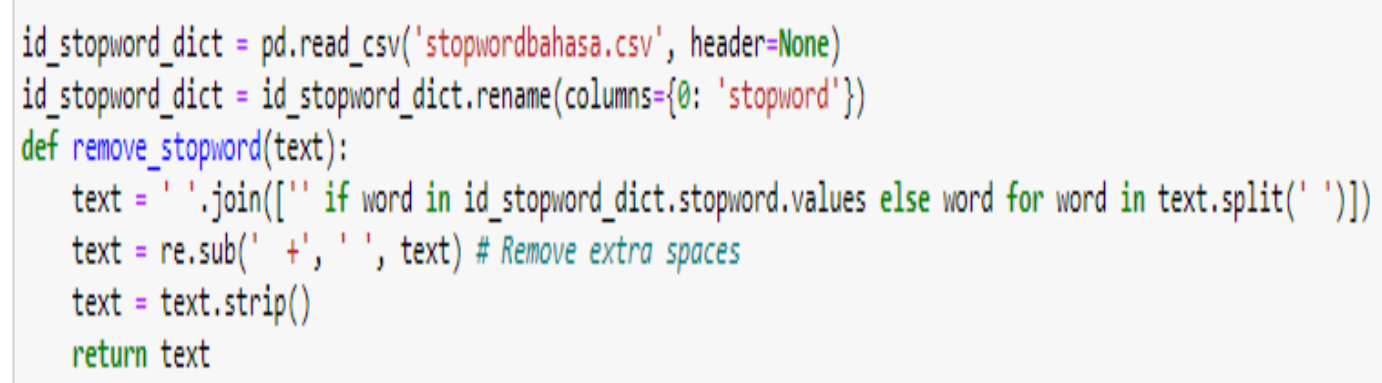

Gambar 9. Menghapus Stop Words 
Tabel 6. Sebelum dan Sesudah Stop Words Removal

\begin{tabular}{|l|l|}
\hline \multicolumn{1}{|c|}{ Sebelum } & \multicolumn{1}{|c|}{ Sesudah } \\
\hline $\begin{array}{l}\text { Siapa yang kasih izin? Siapa yang tetap } \\
\text { izinkan? Siapa yang perpanjang izin? }\end{array}$ & $\begin{array}{l}\text { Siapa kasih izin? Siapa izinkan? Siapa } \\
\text { perpanjang izin? }\end{array}$ \\
\hline
\end{tabular}

\section{f. Filter by Length}

Ketika menulis di media sosial khususnya Twitter, seseorang tidak selalu menulis tweet yang berkaitan dengan pemikirannya. Namun terkadang tweet yang ditulis hanya berupa balasan singkat terhadap tweet orang lain ataupun sekadar mention singkat. Pada penelitian ini, data yang memiliki jumlah karakter kurang dari 15 akan dibuang sehingga diolah hanya data yang memiliki panjang lebih dari 15 karakter. Data tweet yang difilter adalah data yang sudah melalui serangkaian proses di atas.

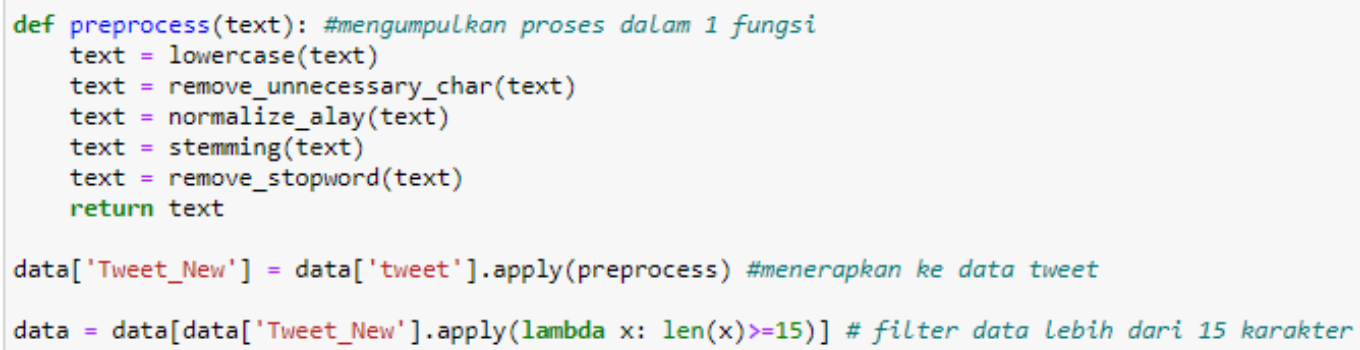

Gambar 10. Menghilangkan Tweet yang Kurang dari 15 Karakter

Tabel 7. Contoh Teks yang Dibuang

\begin{tabular}{|l|l|}
\hline \multicolumn{2}{|l|}{ Preprocessed Tweet } \\
\hline 1 & sepakat mas \\
\hline 2 & haha \\
\hline 3 & terima kasih \\
\hline 4 & usul bagus oke \\
\hline 5 & iya kalem \\
\hline
\end{tabular}

\section{g. Tokenize}

Tokenize adalah proses memecah teks pada suatu kalimat menjadi tokentoken kata. Sebagai contoh kalimat "Budi bermain bola" akan menghasilkan tiga token yaitu "Budi", "Bermain", dan "Bola". Setelah rangkaian sebelumnya dilakukan menggunakan Python, tahap tokenize pada penelitian ini dilakukan 
menggunakan ekstensi text processing pada aplikasi RapidMiner.

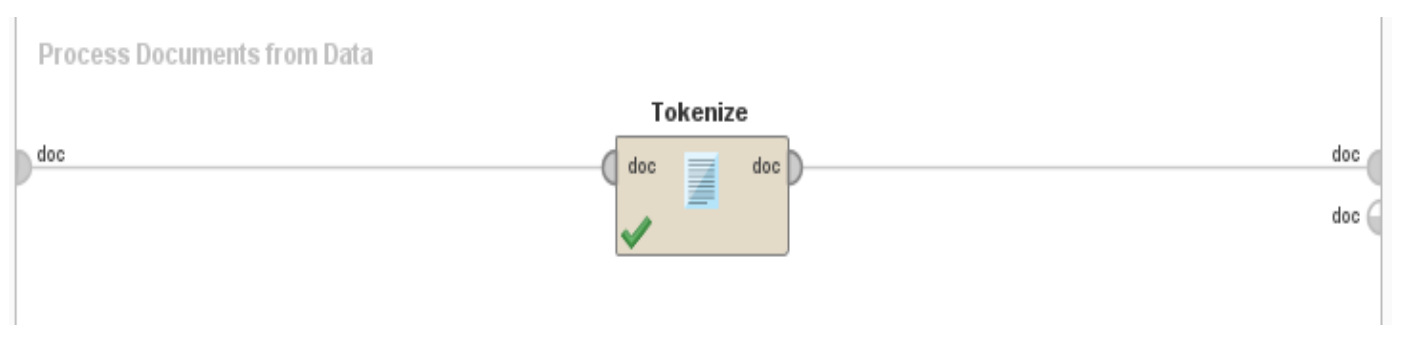

Gambar 11. Tokenize menggunakan RapidMiner

\section{Modelling}

Setelah data melalui proses preprocessing, tahap selanjutnya adalah Modelling. Tahap ini merupakan fase pemodelan menggunakan algoritma Naive Bayes dan Support Vector Machine. Proses ini menggunakan metode 10-fold cross validation. Yang mana dataset dibagi menjadi 10 bagian, kemudian data dipisahkan menjadi dua buah subset, 1 bagian menjadi data uji dan 9 bagian sisanya menjadi data latih. Proses ini diulang ke setiap bagian pada data sehingga diperoleh hasil terbaik dari model yang digunakan. Berikut desain pemodelan yang dilakukan dengan aplikasi RapidMiner:

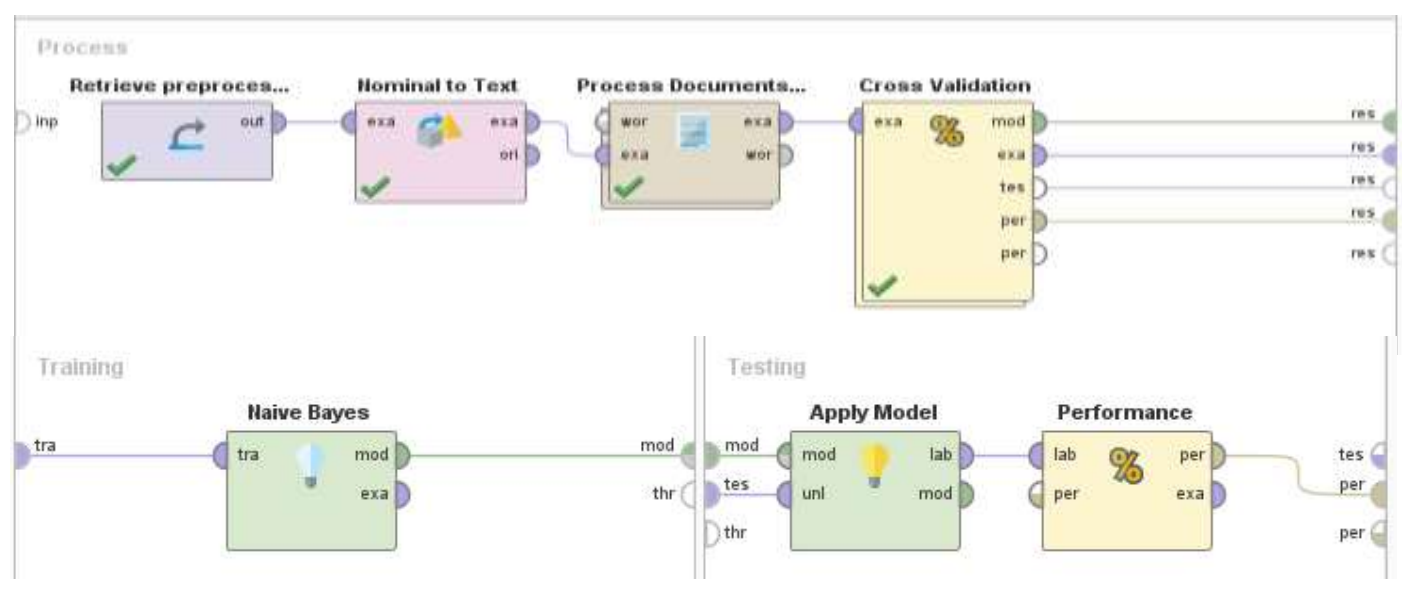

Gambar 12. Modelling menggunakan Naive Bayes 


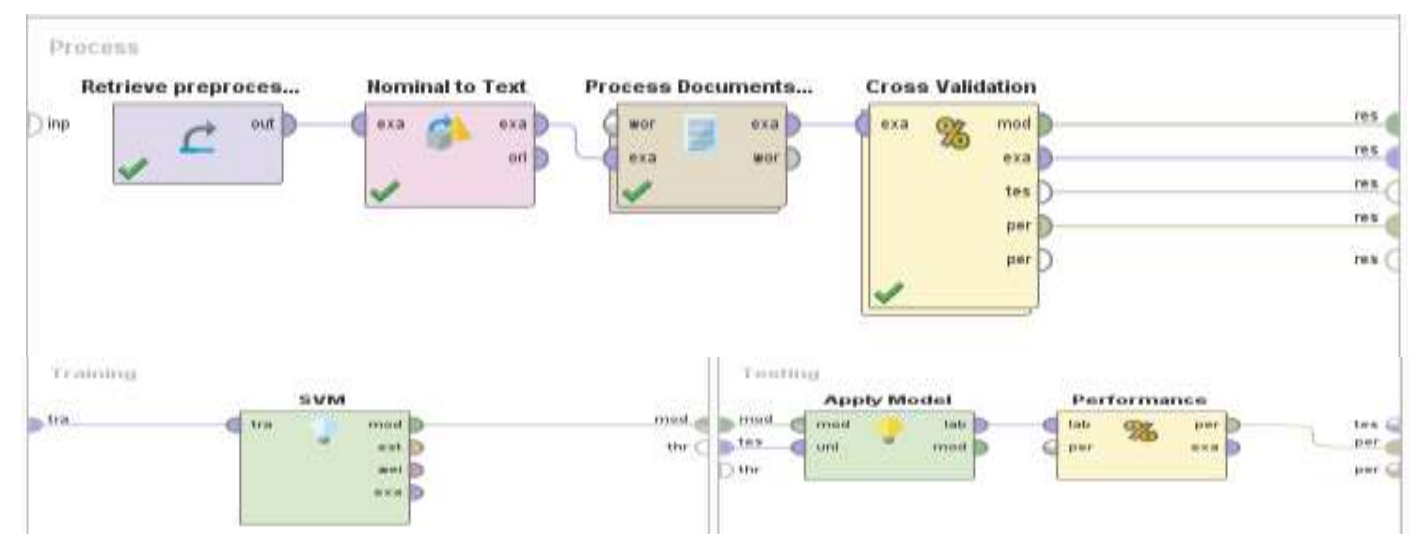

Gambar 13. Modelling menggunakan Support Vector Machine

\section{Evaluation}

Setelah dilakukan pemodelan, tahap selanjutnya adalah melakukan evaluasi dari model yang telah dimasukkan dengan melihat nilai AUC, Accuracy, Precision, dan Recall dari masing-masing metode.

a. Model Naive Bayes

Hasil pengujian menggunakan metode Naive Bayes menghasilkan AUC sebesar 0.748. Akurasi yang didapatkan adalah $76.92 \%$, precision pada prediksi GNPF-Ulama sebesar $73.96 \%$ dan recall sebesar $82.24 \%$, precision pada prediksi NU sebesar $80.58 \%$ dan recall sebesar $71.79 \%$

\begin{tabular}{|l|l|l|l|}
\hline \multicolumn{1}{|l|}{ Tabel 8. Confussion Matrix Naive Bayes } \\
\hline & \multicolumn{1}{|c|}{ true GNPF-U } & true NU & class precision \\
\hline pred. GNPF-U & 125 & 44 & $73,96 \%$ \\
\hline pred NU & & & \\
\hline class recall & 27 & 112 & $80,58 \%$ \\
\hline
\end{tabular}




\section{P-ISSN $2580-7781$}

E-ISSN $2615-3238$

AUC: $0.748+/-0.102$ (micro average: 0.748 ) (positive class: NU)

\section{-ROC — ROC (Thresholds)}

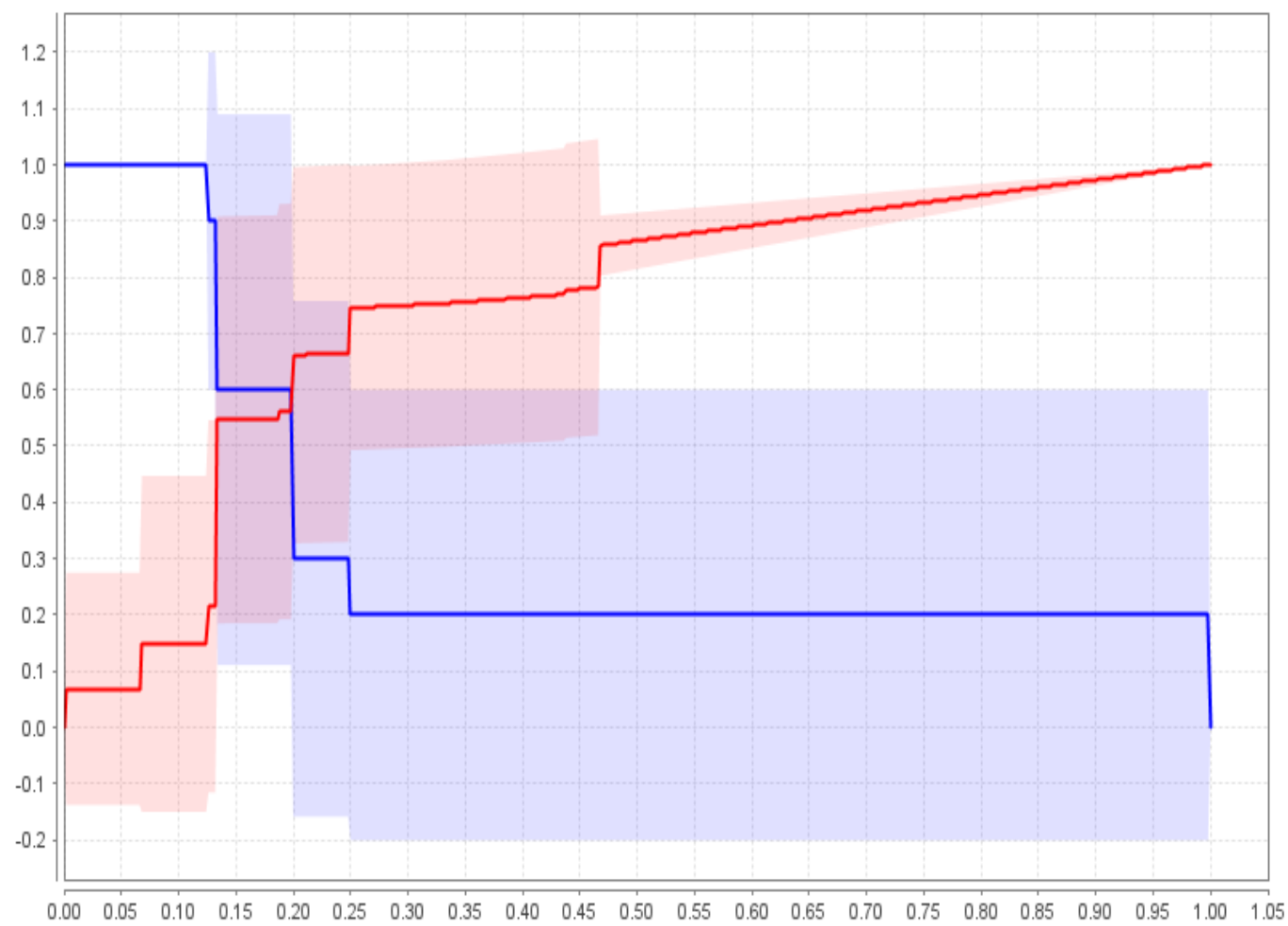

Gambar 14. Kurva ROC Naive Bayes

\section{b. Model Support Vector Machine}

Hasil pengujian menggunakan metode Support Vector Machine menghasilkan AUC sebesar 0.863. Akurasi yang didapatkan adalah 77.28\%, precision pada prediksi GNPF-Ulama sebesar $73.56 \%$ dan recall sebesar $84.21 \%$, precision pada prediksi NU sebesar $82.09 \%$ dan recall sebesar $70.51 \%$.

Tabel 9. Confussion Matrix Support Vector Machine

\begin{tabular}{|l|l|l|l|}
\hline & true GNPF-U & true NU & $\begin{array}{c}\text { class } \\
\text { precision }\end{array}$ \\
\hline pred. GNPF-U & 128 & 46 & $73,56 \%$ \\
\hline pred NU & 24 & 110 & $82,09 \%$ \\
\hline class recall & $84,21 \%$ & $70,51 \%$ & \\
\hline
\end{tabular}




\section{P-ISSN $2580-7781$ \\ E-ISSN $2615-3238$}

AUC: $0.863+\mid-0.059$ (micro average: 0.863 ) (positive class: NU)

-ROC —ROC (Thresholds)

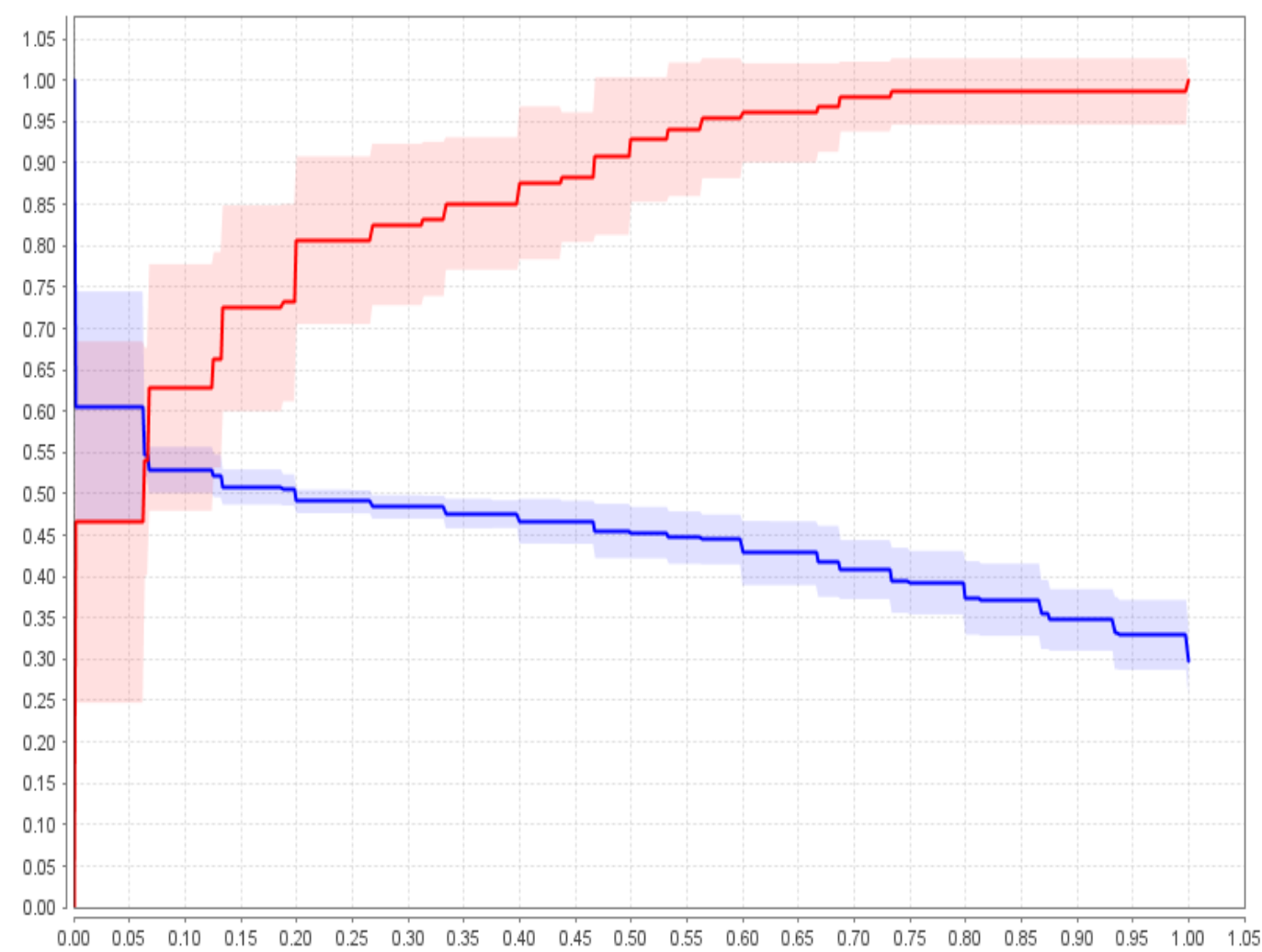

Gambar 15. Kurva ROC Support Vector Machine

Perbandingan Hasil Naive Bayes dan Support Vector Machine

Berdasarkan hasil pengujian di atas, didapat perbandingan akurasi dan AUC sebagai berikut:

Tabel 10. Komparasi Hasil Pengujian

\begin{tabular}{|l|l|l|}
\hline \multicolumn{1}{|c|}{ Algoritma } & \multicolumn{1}{|c|}{ Accuracy } & \multicolumn{1}{c|}{ AUC } \\
\hline Naive Bayes & $76.92 \%$, & 0.748 \\
\hline Support Vector Machine & $77.28 \%$ & 0.863 \\
\hline
\end{tabular}

Pengujian menggunakan metode Support Vector Machine mendapatkan akurasi yang lebih baik dibandingkan metode Naive Bayes dengan hasil $77.28 \%$ berbanding dengan 76.92\%. Nilai AUC pada metode Support Vector Machine juga mendapat hasil lebih baik dibanding Naive Bayes dengan nilai 0.863 berbanding dengan 0.748 , dari nilai tersebut maka performa pada metode Support 
P-ISSN 2580 - 7781

E-ISSN $2615-3238$

Vector Machine sudah termasuk ke dalam good classification, adapun performa pada metode naive bayes termasuk ke dalam fair classification (Gorunescu, 2011).

Dari pengujian di atas juga didapatkan hasil recall (sensitifitas) pada masing-masing label. Recall pada prediksi GNPF-Ulama menjawab pertanyaan "Berapa persen tweet yang diprediksi dari kelompok GNPF-Ulama dibandingkan dengan keseluruhan tweet dari GNPF-Ulama?", recall pada prediksi NU menjawab pertanyaan "Berapa persen tweet yang diprediksi dari kelompok NU dibandingkan dengan keseluruhan tweet dari NU?". Hasilnya adalah recall pada prediksi GNPF-Ulama lebih baik dengan nilai 82.24\% menggunakan Naive Bayes dan $84.21 \%$ menggunakan Support Vector Machine dibandingkan dengan $71.79 \%$ dan $70.51 \%$ pada prediksi NU.

Sehingga berdasarkan hasil di atas, dapat disimpulkan bahwa baik metode Naive Bayes ataupun Support Vector Machine bisa mengklasifikasikan data tweet dari kelompok NU dan GNPF-Ulama dengan cukup baik. Namun model pengujian menggunakan metode Support Vector Machine memiliki kinerja yang lebih baik dibandingkan model yang menggunakan metode Naive Bayes. Dan kinerja kedua metode dalam memprediksi tweet dari kelompok GNPF-Ulama lebih baik daripada prediksi tweet dari kelompok NU.

\section{PENUTUP}

\section{Kesimpulan}

Berdasarkan hasil penelitian yang telah dilakukan mengenai klasifikasi tweet Influencer NU dan GNPF-Ulama di media sosial Twitter, dengan dataset yang terdiri dari 308 tweet setelah melalui rangkaian proses preprocessing, metode klasifikasi naive bayes mendapatkan akurasi sebesar $76.92 \%$ dan AUC sebesar 0.748 (fair classification). Sedangkan metode klasifikasi support vector machine mendapatkan akurasi sebesar $77.28 \%$ dan AUC sebesar 0.863 (good classification). Sehingga bisa disimpulkan bahwa model yang menggunakan metode support vector machine memiliki kinerja yang lebih baik pada penelitian ini dibandingkan dengan metode naive bayes. 
Pada penelitian ini juga, berdasarkan nilai recall dari masing-masing label, tweet dari kelompok GNPF-Ulama bisa diprediksi lebih baik dibandingkan dengan tweet dari kelompok NU, dengan nilai $82.24 \%$ berbanding dengan $71.79 \%$ pada metode naive bayes dan $84.21 \%$ berbanding dengan $70.51 \%$ pada metode support vector machine.

\section{Saran}

Untuk penelitian selanjutnya, penulis menyarankan untuk menggunakan sampel dataset yang lebih besar agar bisa lebih mewakili populasi dari objek penelitian. Selain itu, masih terdapat metode klasifikasi lain seperti decision tree dan $k$-nearest neighbor yang juga bisa digunakan untuk perbandingan lebih lanjut. Berbagai variasi seleksi fitur seperti Term Frequency, TF-IDF, dan Term Occurences juga bisa digunakan pada penelitian selanjutnya.

\section{DAFTAR PUSTAKA}

Baydhowi, Muhamad, Widya Apriliah, and Ilham Kurniawan. 2019. "Klasifikasi Tweet Berdasarkan Keterkaitan Tweet Terhadap Topik Tertentu Pada Twitter Menggunakan Naïve Bayes." Information System for Educators and Profesionals, 4(1): 95-103.

Farih, Amin. 2016. "Nahdlatul Ulama (NU) Dan Kontribusinya Dalam Memperjuangkan Kemerdekaan Dan Mempertahankan Negara Kesatuan Republik Indonesia (NKRI).” Walisongo, 24(2): 251-84.

Gorunescu, Florin. 2011. Data Mining : Concepts, Models and Techniques. eds. Janusz Kacprzyk and Lakhmi C. Jain. Berlin: Springer.

Ibrohim, Muhammad Okky, and Indra Budi. 2019. "Multi-Label Hate Speech and Abusive Language Detection in Indonesian Twitter." In 3rd Workshop on Abusive Language Online, Florence: ALW3, 46-57. https://www.aclweb.org/anthology/W19-3506.pdf.

Jayanto, Dian Dwi. 2019. "Mempertimbangkan Fenomena Populisme Islam Di Indonesia Dalam Perspektif Pertarungan Diskursif: Kontestasi Wacana Politik Antara Gerakan Nasional Pengawal Fatwa Ulama (GNPF-Ulama) Dan Nahdlatul Ulama (NU)." Jurnal Filsafat 29(1): 1-25. https://journal.ugm.ac.id/wisdom/article/view/41131.

Jollyta, Deny, William Ramdhan, and Muhammad Zarlis. 2020. Konsep Data Mining Dan Penerapan. Sleman: Deepublish Publisher.

Oswin Rahadiyan Hartono. 2016. "Indonesian Stoplist.". [Online] 
https://www.kaggle.com/oswinrh/indonesian-stoplist [29 November 2020].

Purnamasari, Ni Made Gita Dwi, M Ali Fauzi, Indriarti, and Liana Shinta Dewi. 2018. "Identifikasi Tweet Cyberbullying Pada Aplikasi Twitter Menggunakan Metode Support Vector Machine ( SVM ) Dan Information Gain ( IG ) Sebagai Seleksi Fitur." Jurnal Pengembangan Teknologi Informasi dan Ilmu Komputer, 2(11): 5326-32.

Suyanto. 2019. Data Mining : Untuk Klasifikasi Dan Klasterisasi Data. Bandung: Informatika.

Tala, F Z. 2003. Universiteit van Amsterdam The Netherlands "A Study of Stemming Effects on Information Retrieval in Bahasa Indonesia.". [Online]. https://eprints.illc.uva.nl/740/1/MoL-2003-02.text.pdf. 